\title{
LA MALETA DE CERVANTES
}

El ventero Palomeque ama la literatura de evasión. Y no es un caso aislado en su venta, donde parece haberse dado cita una caterva de lectores entusiasmados con los libros de caballerías: su mujer, su hija, Maritornes, los segadores de paso, etc. Los buenos ratos que la lectura colectiva de las gestas caballerescas les procu$\mathrm{ra}$, en las cortas noches del verano manchego, se los deben a un viajero descuidado que olvidó su maleta, repleta de libros y manuscritos, en la venta. Palomeque, por supuesto, no conoce el nombre del transeúnte desmemoriado, pero a nosotros, a los lectores modernos del Quijote, no se nos escapa que se trata del propio autor de la obra ${ }^{1}$. Gozamos de una ventaja respecto al ventero, y es que sabemos que, unos años más tarde, uno de los manuscritos de la maleta, el que lleva por título Novela de Rinconete y Cortadillo, fue publicado en una colección de novelas a las que su autor quiso calificar de «ejemplares». En otras palabras, nosotros hemos leído lo que a Palomeque nadie le leyó; nuestro conocimiento de lo no narrado en el Quijote nos permite identificar al dueño de la maleta, o mejor, al autor del manuscrito, aunque no hay por qué imaginar que sean personas diferentes.

Satisfecha así la primera exigencia de la pesquisa policiaco-literaria que les propongo, es decir, una vez establecida la identidad del viandante, nuestro próximo paso, en cuanto tribunal encargado de instruir el auto de procesamiento, será la comprensión de los

1 Desveló el arcano MAURICE MolHo, "Manuscritos hallados en una venta», en Actas del tercer coloquio internacional de la Asociación de Cervantistas. Barcelona, Anthropos, 1993, pp. 57-68. 
motivos del olvido de la maleta y el móvil de la fechoría, si es que la hubo. En caso de que llegáramos a establecer fehacientemente la existencia de un delito - un atentado al patrimonio nacional ocasionado por la pérdida de importantes manuscritos-, al encausado se le debería aplicar el agravante de la alevosía, pues con su acción impone la presencia en el texto del Quijote de El curioso impertinente, sin que ninguno de los presentes en la venta, ni de los futuros lectores, se pueda oponer a su lectura pública. En su descargo alegaría yo la clemencia que, a pesar de todo, demuestra para con nosotros al no "ingerir [la otra] novela suelta y pegadiza» II, $44,907^{2}$ ) que anuncia.

Habría que añadir aún al sumario del auto los demás casos de pérdida de manuscritos, en copia única. Inexistente aún el aparato probatorio, los cargos contra el imputado se configuran, por lo tanto, como vilipendio del tesoro nacional y lesa literatura. Soy consciente de que a alguien le parecerá excesivo formular tamañas imputaciones para un suceso tan intranscendente - aunque significativo- como el hallazgo por don Quijote y Sancho de unos poemas y un libro de memorias en una maleta perdida en Sierra Morena, pero no hay que olvidar que nos las veremos, otrosí, con un lance análogo, aunque de mayor envergadura, del que depende nada menos que la transmisión y conservación para la posteridad de la obra maestra de nuestra literatura nacional; me estoy refiriendo, como vds. seguramente ya habrán adivinado, al manuscrito arábigo contenido en unos cartapacios, casualmente hallado en el Alcaná de Toledo por el anónimo segundo autor de la historia de don Quijote. En todos estos casos, quier por la negligencia de alguno (el viajero), quier por la insania de otro (Cardenio), quier por la ignorancia de los más (que no supieron apreciar el valor del manuscrito arábigo), a pique estuvimos, estimado auditorio, de perder una de las joyas de nuestra literatura patria, o cuando menos de una parte de la misma.

La hipótesis investigativa de la que partiré propone que el encausado, al diseminar deliberadamente por la geografía nacional sus manuscritos, pretendió difundir sus ideas revolucionarias sobre la literatura, y obligar a los ignaros fruentes de los mismos a reflexionar sobre ellas y a amoldar los textos de su cultura literaria presente y futura a dichos presupuestos teóricos. Lo acuso, además, de ser el ideólogo y promotor de una nueva concepción de la escritura que hizo tabla rasa de los tradicionales conceptos de "autor», «autoridad» y «autoría». Lo inculpo de que, a consecuencia de su

2 La referencia - y de aquí en adelante, igual - es a la parte, capítulo y página de la edición de MARTín DE RIQUer. Barcelona, Planeta, 1972. 
persistente labor de dispersión de textos y difuminación de las fronteras de la personalidad narratorial, se instauró un nuevo género de escritura en el que todas las voces y todas las visiones del mundo tuvieron cabida. A consecuencia de sus acciones, se perdieron los vínculos entre el texto y la autoridad social, entre lo escrito y el tiempo, y a punto estuvo de perderse también el nexo entre la obra y el nombre de su autor. Y todo ello, con la finalidad oculta de dar mayor realce a su persona, trascender los límites temporales e ingresar en la zona reservada a los inmortales.

\section{LAS HUELlaS DACTILARES DE CERVANTES}

Será bueno recordar que contamos con otras pruebas, así sean indirectas, de la autoría del delito, pues la impericia del llamado Manco de Lepanto le lleva a dejar sus huellas dactilares en varios lugares del texto del Quijote. De nada le servirá, por tanto, a Miguel de Cervantes reconocerse no más que padrastro, que no padre, del «hijo seco, avellanado, antojadizo y lleno de pensamientos varios y nunca imaginados de otro alguno", [I, prólogo, 11], si los personajes de su obra, casi a renglón seguido, hacen repetidas referencias a su nombre: el cura inquisidor de caballerías confiesa que «es grande amigo [suyo] ese Cervantes» [I,6,80], y el cautivo en la venta nos da noticia de "un soldado español, llamado tal de Saavedra» $[\mathrm{I}, 40,437]$. Bien es verdad que ambos testigos no declaran sino conocer a una persona que fue soldado y es escritor, y que de ningún modo la relacionan con el texto que les contiene; pero no es menos cierto que, siendo éste el único nombre de persona real contenido en el Quijote, y siendo ambos testigos de nacionalidad "quijotiana», han de apuntar forzosamente hacia el nombre inscrito en la portada del libro que les da la razón de ser y tiende un puente entre su mundo posible y el mundo real. Su acto de gratitud les hace honor, qué duda cabe, pero revela, a la vez, el interés de la persona aludida por conseguir que su nombre aparezca, así sea de modo oblicuo, en el interior del libro que él firma, también de modo oblicuo, cuando en el frontispicio del mismo se declara no más que su compositor - volveremos sobre este aspecto más adelante-.

Cervantes graba en filigrana su nombre en la historia escrita por él. Su modo de estar presente en el texto es en la lectura en palimpsesto. A partir de las fases de escritura, podríamos representar un texto como una pirámide invertida, constituida por la superposición de los diferentes niveles de elaboración, distribuidos como sigue: el primer nivel del manuscrito estaría constituido por la vo- 
luntad de decir del autor, su nombre repetido como compendio de todos los contenidos enunciables; en el segundo nivel hallaríamos una primera exposición de los temas y el tono elegidos para la circunstancia, bajo forma de oposiciones semánticas generativas, y en uno sucesivo -que puede ser el tercero, si ya las reglas de transformación de su intención han convertido en literatura su impulso inicial- los temas y el tono se articularían en el discurso coherente de la ficción narrativa. Pues bien, tanto el cautivo como el cura - los dos testigos de cargo del proceso- consiguen leer, desde dentro de su mundo posible, el nivel profundo del palimpsesto, donde se trasluce la filigrana del nombre del autor. También los personajes de la Biblia, la escritura por excelencia, consiguen leer en transparencia el nombre del Autor Primero del libro que les contiene. Pero no quiero perjudicar ulteriormente al acusado, aumentando el ya notable peso de sus cargos con los de idólatra, sacrílego, impostor divino y desacralizador supremo que constriñe a los personajes de su libro a ser cómplices de su parodia del Sumo Texto. No renunciaré, en cambio, a exponer los primeros considerandos acerca de este modo de firma sin rúbrica con que Cervantes marca su obra.

\section{LA FIRMA ES SEÑAL Y MARCA DEL AUTOR}

Pero no era necesario que los personajes mencionaran el nombre de su autor en vano, o casi, para que nos percatáramos de que el gran ausente del texto ${ }^{3}$, aquel que, en cuanto autor de la escritura, se somete al proceso de evanescencia personal progresiva que caracteriza su ejercicio ${ }^{4}$, era Cervantes. En la portada de la edición de 1605 se dice que el libro fue «compuesto por Miguel de Cervantes Saavedra», lo cual, si por un lado le atribuye la paternidad del escrito, por el otro, al no designarle explícitamente como su escritor o ideador, sino solo como "compositor» ${ }^{5}$, le enajena la responsabilidad del mismo. En cierto sentido, la transcripción de su nombre en la portada podría equivaler a una firma, una marca de propiedad, sin la personalización de la rúbrica que señala inequívocamente hacia el individuo que la produce.

3 Cfr. JACQues DERridA, "Firma evento contesto», en Margini, [Marges de la philosophie, 1972]. Torino, Einaudi, 1997, pp. 393-424, [p. 404 y ss.].

${ }_{4} \mathrm{El}$ autor se va diluyendo en su texto, hasta desaparecer; es lo que afirma ROLAND BARTHES, "La morte dell'autore», en Il brusio della lingua, [Le bruissement de la langue, 1984]. Torino, Einaudi, 1988, pp. 51-56.

5 Resumo aquí algunas de las ideas expuestas por MAURICIO MOLHO en El nombre tachado. Limoges, Faculté des Lettres et des Sciences Humaines, 1989. 
En la firma de un autor confluyen sus dos grandes funciones textuales, la de la autoridad, es decir, la responsabilidad por lo dicho en el libro, y la de la autoría, la paternidad de la obra; la primera le atribuye la intención del texto, la segunda incluye el texto en el álveo de sus obras ${ }^{6}$. La firma señala hacia el responsable y marca la obra como perteneciente a un conjunto. En el caso de la firma en filigrana que acabamos de ver, se pierde la señal, la rúbrica, y permanece la marca, la transcripción del nombre: se reconoce la autoría de Cervantes, sin atribuirle directamente la responsabilidad de lo dicho. Que es la misma operación que él realiza con la cita de los títulos de sus obras dentro del Quijote y con el acto de dejación de autoridad del prólogo. Me explico mejor.

La Galatea, La Numancia y Rinconete y Cortadillo son las tres obras de Cervantes citadas en el Quijote. La primera le es atribuida directamente en la portada del libro que el barbero hojea durante el escrutinio de la biblioteca de don Quijote (I,6,80). El objeto editorial lleva la firma del autor en el frontispicio. La Numancia, en cambio, es aducida, por el cura, en conversación con el canónigo de Toledo, como ejemplo de aplicación feliz de los preceptos aristotélicos (I,48,523). Rinconete y Cortadillo es uno de los manuscritos que el cura hubiera podido leer en la venta de Palomeque, después o en lugar de la lectura de El curioso impertinente; no será así, y gracias a ello hemos podido descubrir, ya lo dije, la identidad del viajero. En los tres casos, el eco de los títulos pronuncia el nombre del autor; casi se podría leer en anagrama la palabra «Cervantes» en los nombres de los libros. En los tres casos, la mención de otras obras de Cervantes en el interior del Quijote les atribuye la misma autoría, marca los textos como propiedad del mismo autor, pero sin señalarle directamente como responsable de ellos; de La Galatea se dice que es de Cervantes en un libro, el Quijote, que no le reconoce como padre; de La Numancia y Rinconete y Cortadillo, ni siquiera eso. Si el autor incluye El curioso impertinente y está a punto de incluir Rinconete y Cortadillo, es... porque son suyos, así que la desposesión intratextual de autoría no

6 Este ministerio fiscal no puede por menos que reconocer, así sea en nota a pie de página, que el pernicioso influjo del acusado se extiende incluso a él, en lo referente a la grabación en filigrana del propio nombre en el texto, justo antes de recordar que los dos conceptos apenas mencionados, verbigracia: autoridad y autoría, las dos grandes funciones del autor, ya han sido tratados por él en dos alegatos anteriores; a saber: "Autoridad y autoría en el Quijote», en M. ${ }^{\mathrm{a}}$ CRUZ GARCÍA DE ENTERRÍA [ed.], Siglo de Oro. Actas del IV Congreso Internacional de AISO. Alcalá de Henares, Servicio de Publicaciones Universidad de Alcalá, 1998, pp. 1005-1016; y "La débil autoridad del padrastro del Quijote», en Actas del III Congreso Internacional de la Asociación de Cervantistas (III CINDAC), [ed.Antonio Bernat Vistarini]. Palma, Universitat de les Illes Balears, 1998, pp. 277-295. 
tiene sino otra función que la de la negar el significado profundo que aflora en el significante: el autor es el Manco de Lepanto. La máscara de los autores fingidos funciona en la representación narrativa, pero el soporte de la máscara, el cuerpo que la modela por debajo, sigue siendo el mismo y no puede dejar correr la ocasión sin mencionar su presencia. "Habla la máscara, pero en realidad el verdadero autor soy yo», parece decir Cervantes. El lector no puede evitar el movimiento del interior al exterior del texto, donde reconoce el título aludido como perteneciente a la serie cervantina; el suyo es el movimiento contrario al de la maleta, que, según Molho, introduce «en la trama textual del Quijote un espacio de extratextualidad ${ }^{7}$.

Las tres obras mencionadas pertenecen a tres géneros diferentes; siguen sus normas; acatan la ley de su mundo literario; y en cuanto fieles súbditos del rey Canon son recordados por el cura; no ciertamente en cuanto discursos que proponen un mensaje del que el autor se deba responsabilizar; por tanto al cura le basta con reconocerles la paternidad, la autoría, marcarlos con el hierro de la casa.

\section{LA FIRMA SIN RÚBRICA DE DON QUIJOTE}

Don Quijote tampoco reconoce la responsabilidad de la carta que escribe a Dulcinea en Sierra Morena, aunque sí acepta su paternidad, cuando da a Sancho las instrucciones para que la haga transcribir al primer letrado que encuentre:

\footnotetext{
-En lo que toca a la carta de amores, pondrás por firma: «Vuestro hasta la muerte, el Caballero de la Triste Figura». Y hará poco al caso que vaya de mano ajena, porque, a lo que yo me sé acordar, Dulcinea no sabe escribir ni leer, y en toda su vida ha visto letra mía ni carta mía $[\mathrm{I}, 25,265]$.
}

La misiva reproduce los tópicos del amor cortés; se inserta en un filón preexistente y eso exime a don Quijote de su responsabilidad de autor, la autoridad, aunque no de su paternidad, la autoría: él la ha escrito y por tanto ha de llevar su nombre, aunque no vaya de su puño y letra. De tal modo, reconoce indirectamente que se está apropiando del código y no viceversa, que, en vez de incluirse a sí mismo en el código, dejarse perforar por él, convertirse en su portavoz, realiza la operación inversa: perfora él al código y lo obliga a tolerar su visita forzada. Se está reconociendo como dueño de esas

\footnotetext{
7 MolHo, "Manuscritos hallados en una venta», cit., p. 68.
} 
palabras, aunque no su responsable; no es él quien habla a través del código, sino el código, o su parodia, a través de él. El nombre del Caballero de la Triste Figura marca el texto como su propiedad, pero no le señala; de ahí que lo importante sea que Dulcinea relacione el texto con el Caballero, identifique la marca reproducible del nombre y no la señal inimitable de la rúbrica.

El caso opuesto, en cierto sentido, desde el punto de vista de la autoría de lo escrito, es el de Sancho, que no sabe escribir, pero sabe firmar:

\footnotetext{
- Bien sé firmar ni nombre - respondió Sancho-, que cuando fui prioste en mi lugar, aprendí a hacer unas letras como de marca de fardo, que decían que decía mi nombre [II,43,904].
}

Sancho es completamente extraño al código de la escritura, que ni le pertenece ni le condiciona; son los demás los que tienen que atribuir un significado a su firma. Él se conforma con la deíxis implícita en la misma; no le interesan ni la responsabilidad de lo escrito, ni la paternidad; basta que las letras le señalen a él. Su firma no es más que una señal sin contenido. Equivale, por tanto, a una simple rúbrica, la señal inconfundible, que se opone a la firma en cuanto transcripción del nombre, según don Quijote, cuando ha de resolver el problema de la autenticación de la cédula de pollinos:

\footnotetext{
- No es menester firmarla - dijo don Quijote-, sino solamente poner mi rúbrica, que es lo mesmo que firma, y para tres asnos, y aun para trecientos, fuera bastante [I,25,287].
}

Don Quijote, por tanto, ve en la firma no más que una marca de propiedad y en la rúbrica una señal de responsabilidad. Las dos características son convenientemente aprovechadas por él para evitar, sin la rúbrica, la autoridad responsable de la carta y para restituírsela, con ella, a la cédula de pollinos ${ }^{8}$.

\section{EL PROLOGUISTA FIRMA SIN RÚBRICA}

La misma actitud de don Quijote hacia la firma es, con las debidas proporciones, la del autor del Quijote, cuando en el prólogo renuncia a la autoridad que le compete y la traslada al amigo parlero que oportunamente le visita. Si la voz del autor estuviera im-

8 En la interpretación de Gonzalo Torrente Ballester (El Quijote como juego. Madrid, Guadarrama, 1975, p. 128), don Quijote evita firmar la cédula para no tener que declarar en un documento público si es don Quijote o Alonso Quijano y poder continuar con el juego teatral que mantiene desde el principio. 
buida de la fuerza de su autoridad, no necesitaría un portavoz que resumiera el mensaje de su libro, su utilidad para el lector. No renuncia, en cambio, a la autoría, cuando, a coloquio con el lector, se declara "padrastro» del libro en cuestión, asumiendo su paternidad, aunque de forma un tanto dislocada. El silencio del autor en el pasado de la escritura del prólogo («muchas veces tomé la pluma para escribille, y muchas la dejé», [I, prólogo, 12]) se transforma en discurso prolijo del presente de la lectura de su destinatario ("esta prefación que vas leyendo», [Ibidem]). El prologuista ha mantenido la voluntad de decir, por encima de su incapacidad pasada de hacerlo; desamparado por la autoridad de la voz, se transforma en su voluntad expresiva, en el presente eterno de la lectura, donde pervive el eco de su voz al lado del lector («esta prefación que vas leyendo", [Ibidem]). El autor se deja transportar por su libro a casa del lector, se deja contener por él, se deja identificar con él; de tal manera crea una figura intemporal, la de su querer decir, que salta por encima de las barreras del tiempo, gracias al rechazo de la autoridad del autor, que le ha permitido diluir su presencia en el texto, y hacerse con el texto mismo a medida que éste se va haciendo, prerrogativa de los autores modernos, según Barthes ${ }^{9}$. El texto se convierte en una especie de maleta abandonada en la casa del lector por el autor, la instancia escritural que suplanta la persona del escritor, que transforma en presencia de la intención del verbo la ausencia irremediable del escritor. En un momento de distracción del anfitrión, el autor se instala en su texto y se dispone a gozar de las ventajas que le ofrece la posesión de un territorio verbal por el que no pasa el tiempo. Y, sin más ni más, con artes de prestidigitador, introduce su propio cuerpo en el texto que está prologando: «la pluma en la oreja, el codo en el bufete y la mano en la mejilla», [Ibidem]. El autor-prologuista reclama para su texto la misma forma de verificación del relato del narrador oral, es decir, la que le confiere la presencia de su enunciador ${ }^{10}$; pero, sobre todo, marca el texto con la firma de su cuerpo, a la vez que renuncia a la rúbrica, la deíxis que le señalaría como responsable.

\section{RETORNO A LAS MALETAS}

Para Foucault ${ }^{11}$, el nombre de un autor no es más que el contenedor de la coherencia estructural, temática y estilística de dife-

9 BARTHES, «La morte dell'autore», cit.

10 Cfr. Paul Zumthor, La presenza della voce. Introduzione alla poesia orale, [Introduction à la poésie orale, 1983]. Bologna, Il Mulino, 1984, p. 31.

11 He consultado la versión italiana del artículo: Michel FoucaulT, "Che cos'è un autore», Scritti letterari. Milano, Feltrinelli, 1984, pp. 1-21. 
rentes obras. El nombre de Cervantes en boca de sus personajes, al igual que la alusión a él contenida explícita o implícitamente en las citas de los títulos de sus obras, funciona, en efecto, como catalogador de textos. Así como don Quijote consiente que otro firme en su nombre, Cervantes se abstrae de su texto, nos sustrae la señal de su identidad, no se señala a sí mismo con una rúbrica y deja simplemente que otros le menten; es como si hubiera olvidado su nombre, el continente de sus obras, en la boca de sus personajes, al igual que había olvidado el otro continente de sus obras, la maleta, en la venta de Palomeque. Estas consideraciones nos devuelven del proceso por indicios al análisis de las pruebas en nuestro poder, que son las que fundamentan el proceso de lesa literatura que estamos instruyendo contra el Manco de Lepanto.

Alguien podría argumentar, señores oidores -o lectores-, que en la valija de la venta se guardan también obras ajenas al mencionado Manco de Lepanto, concretamente algunos libros de caballerías que dan pie a la nueva contienda en torno al género. Pero nosotros no debemos olvidar que junto con ellos se conservan unos papeles, "hasta obra de ocho pliegos escritos de mano» [I,32,352], con la Novela del Curioso impertinente y en un bolsillo recóndito otra novela más de Cervantes; escuchemos la voz del narrador, al describir las pruebas de cargo:

El ventero se llegó al cura y le dio unos papeles, diciéndole que los había hallado en un aforro de la maleta donde se halló la Novela del curioso impertinente, y que, pues su dueño no había vuelto más por allí, que se los llevase todos; que, pues él no sabía leer, no los quería. El cura se lo agradeció, y, abriéndolos luego, vio que al principio de lo escrito decía: Novela de Rinconete y Cortadillo, por donde entendió ser alguna novela y coligió que, pues la del Curioso impertinente había sido buena, que también lo sería aquélla, pues podría ser fuesen todas de un mesmo autor; y así, la guardó, con prosupuesto de leerla cuando tuviese comodidad $[\mathrm{I}, 47,513]$.

El ventero entrega a destiempo el manuscrito de Rinconete $y$ Cortadillo; se acaban de despedir todos; ya no hay tiempo para lecturas; más tarde, en su casa y a solas, el cura probablemente comprobará que su intuición sobre la calidad literaria y la autoría del escrito era acertada. La finalidad de la alusión a la novela que verá la luz solamente ocho años más tarde es evidentemente propagandista; el autor pretende completar su imagen literaria desplegando sus realizaciones en varios campos. Por el mismo procedimiento, el ventero hubiera podido extraer las obras completas de Cervantes de la cornucopia literaria que parece ser la maleta abandonada, un continente literario de la misma capacidad que el nombre del autor. Antes he citado a Foucault como testigo de cargo y ahora lo 
vuelvo a convocar para sugerir que la maleta abandonada en la venta no es más que una metáfora del nombre del autor ${ }^{12}$. El modo en que Cervantes los trata es análogo: olvida su nombre y su maleta en la boca y la casa de los demás; renuncia a declarar con precisión su propiedad; los presenta de modo oblicuo (el prólogo por boca del amigo que le visita, la maleta hallada, su nombre mencionado de pasada por sus personajes). La función de ambos es también análoga: marcan la paternidad, la autoría, sin señalar la autoridad de Cervantes, su responsabilidad directa sobre lo dicho. Ambos delimitan un espacio que alberga la expresión de la intimidad del portador, así se reduzca ésta a meras camisas - la prenda en contacto directo con la piel-, lo que no es el caso de la maleta de la venta, pero sí lo es de la de Cardenio, que contiene, según el registro llevado a cabo por nuestro ujier Sancho Panza:

Cuatro camisas de delgada holanda y otras cosas de lienzo, no menos curiosas que limpias, y en un pañizuelo halló un buen montoncillo de escudos de oro. [...] Y buscando más, halló un librillo de memoria, ricamente guarnecido. Este le pidió don Quijote, y mandóle que guardase el dinero y lo tomase para él $[I, 23,235]$.

En dicho libro lee don Quijote sonetos, cartas y otras expresiones de la intimidad de su dueño, Cardenio, «a quien podemos llamar el Roto de la Mala Figura - como a don Quijote el de la Triste-» $[\mathrm{I}, 23,244]$, tan roto como su propia maleta, la cual «aunque [...] venía cerrada con una cadena y su candado, por lo roto y podrido della vio [Sancho] lo que en ella había» $[\mathrm{I}, 23,235]$. El paralelo entre la maleta y su dueño sigue siendo válido, los dos están rotos: Cardenio por fuera, en sus harapos, y por dentro, en la razón, que deja ver los recovecos de la locura; su maleta rota y podrida también deja ver su interior, a pesar de ir bien cerrada, con una cadena y un candado, como debían ir las maletas, según el Tesoro de Covarrubias ${ }^{13}$, y como iba en efecto la de la venta, que era «una maletilla vieja, cerrada con una cadenilla». Así debía haber cerrado la suya el compañero de viaje de Cortadillo, sin que le valiera de nada, pues, haciendo honor a su nombre,

no se pudo contener Cortado de no cortar la valija o maleta que a las ancas traía un francés de la camarada; y así, con el de sus cachas le dio tan larga y profunda herida, que se parecían patentemente las entrañas, y sutilmente le sacó dos camisas buenas, un reloj de sol y un librillo de memoria ${ }^{14}$.

\footnotetext{
12 Ibidem

13 Sebastián de Covarrubias Orozco, Tesoro de la lengua castellana o española, ed. de MARTín DE RIQUER. Barcelona, Alta Fulla, 1998, sotto voce "maleta".

${ }_{14}$ Novela de Rinconete y Cortadillo, en Novelas ejemplares, vol. I, ed. de HARRY Sieber. Madrid, Cátedra, 1985, pp. 189-240, [p. 199].
} 
Y aquí solicito un momento de atención por parte del auditorio para observar la singular coincidencia entre los objetos de las maletas de ambos viajeros; tan singular me resulta que, a no tener yo tan buena opinión de Cardenio, diérame a sospechar que fue él el último beneficiario del robo de Cortado, antes de que emprendiera el viaje a Sierra Morena con la valija desvalijada del francés de marras, después de haber vendido el reloj de sol, del que recabó los escudos de oro que tan alegre pusieron a Sancho, y después de haber impedido la lectura en la venta de la novela de Rinconete $y$ Cortadillo, para evitar que se descubriera la procedencia de sus escritos y su maleta. Pero no quiero desviar el rumbo de nuestras pesquisas, orientadas hacia el autor del relato, con estas sospechas -no del todo fundadas, he de reconocerlo- sobre la actividad de perista de uno de los personajes.

\section{LA INTIMIDAD DE LA MALETA}

Cardenio encierra en la maleta su intimidad, su pasado, lo que le saca de casa; condensa su identidad en los pocos objetos literarios que caben en su libro de memorias, su interioridad, y en un par de camisas, el objeto íntimo de su exterioridad. Convertida en objetos, su identidad es transportable; de tal modo él puede controlar su manifestación, ponerle coto, que es su primera tarea en el proyecto de vida que se ha dado; para llevarlo a cabo ha de dominarse a sí mismo, encerrarse en unos límites, que es precisamente lo que hace con los fetiches de su identidad. Desgraciadamente para él, su valija se rompe y se vierte en el exterior. El control sobre su intimidad se ha roto; igual que su razón, su ser interior. Hay otro ejemplo en que se aprecia esa consideración de la maleta como contenedor de lo más recóndito de los personajes, cuando el narrador compara la celada de don Quijote, que le protege el magín, a una maleta:

Detuvo la rienda el caminante, admirándose de la apostura y rostro de don Quijote, el cual iba sin celada, que la llevaba Sancho como maleta en el arzón delantero de la albarda del rucio [II,16,689-90].

Volvamos por un momento a Sierra Morena, para observar cómo don Quijote recicla el diario íntimo de Cardenio como contenedor de sus propias intimidades en la carta a su señora, pero también como soporte material de un documento administrativo: la cédula de pollinos. En cierto sentido se apodera del otro, de su sentir; memoria de loco sobre memoria de loco; escritura en palimpsesto de locuras de amor compartidas. Dice don Quijote: 
-Sería bueno, ya que no hay papel, que la escribiésemos [la carta a Dulcinea], como hacían los antiguos, en hojas de árboles, o en unas tablitas de cera; aunque tan dificultoso será hallarse eso ahora como el papel. Mas ya me ha venido a la memoria dónde será bien, y aun más que bien, escribilla: que es en el librillo de memoria que fue de Cardenio. [I,25,264. Énfasis mío.]

La memoria del caballero se apropia de la de Cardenio y la coloniza hasta tal punto que es con la memoria de Cardenio con la que él piensa. Falta ya poco para que, en aquel mismo lugar, el de la triste figura se comporte como el roto de la mala figura y se rompa también él en sus locuras a imitación de Orlando o Amadís.

Don Quijote escribe sus sentimientos en el libro que encierra las memorias de Cardenio, que a su vez estaba encerrado en la maleta abandonada en la Sierra. Muchos personajes de las obras cervantinas conservan la expresión de su intimidad en un contenedor: el francés que provee a Cortadillo de camisas guarda en su maleta un libro de memorias. Persiles viaja con el lienzo que resume su historia. El alférez Campuzano lleva en su pecho, en un cartapacio, la historia del Coloquio de los perros, lo más secreto de su experiencia reciente - idos perros que hablan!-, tan secreto que necesita doble contenedor, el cartapacio y el pecho. Del pecho de la desmayada Luscinda extrae don Fernando el papel donde declara «ser esposa de Cardenio y no poderlo ser suya» [I,36,433]. La manifestación escrita $-\mathrm{o}$ figurada- de la propia historia interior $-\mathrm{O}$ exterior - necesita un soporte material (libro, lienzo, papel) que la convierta en objeto, presto a ser revelado, descubierto, interpretado en el momento oportuno, y éste necesita un contenedor (maleta, cartapacio, pecho) que se pueda abrir en el instante cumbre y manifestar el objeto que relata la interioridad del personaje. De esta agnición, tan fatigosamente conquistada, no se puede derivar más que la glorificación del poseedor del fetiche, en los casos de los personajes que dominan los resortes de la propia historia. Se puede decir que esa contención de los significados íntimos de la persona dentro de unos límites objetuales dota al individuo del control sobre el propio proyecto y de la necesaria soberanía sobre sí mismo que lo transforma de simple personaje en protagonista.

La voluntad de ser de los personajes, la decisión de afrontar el mundo, de trazar su propio trayecto en él en busca de un equilibrio distinto, les lleva a hacer la maleta, liarse la manta a la cabeza y partir. El mismo don Quijote en su segunda salida se pertrecha de camisas y dinero, como le había sugerido el ventero; recoge también él su impedimenta, porque, después de su iniciación caballeresca, ha comprendido, y con él el autor, que el suyo es un proyecto de tiempos largos; no es casual que sea justamente entonces 
cuando entra en escena Sancho, el referente dialéctico necesario para tan largo viaje.

\section{LA MALETA Y EL PROYECTO DEL AUTOR}

La maleta, por tanto, equivale al proyecto, a la voluntad de ser, y en cuanto tal ha de poner término a la dispersión vital anterior a la decisión de cambio y encauzarla en los límites del proyecto. En términos parecidos ha definido la aumentación de la escritura («autor» viene del latín «augere»: 'aumentar') E. Said ${ }^{15}$, para quien la autoridad del autor se manifiesta en su capacidad de encerrar las molestias, la diversión de la cotidianidad en los límites del proyecto artístico.

Hay, con todo, una diferencia entre los personajes que deciden tomar la propia vida en sus manos y el proyecto narrativo de Cervantes: los personajes, en los manuscritos que contienen sus maletas, se cuentan a sí mismos, fijando su imagen en un elemento, unos episodios, un núcleo irradiador de sí, lo que les expulsa de su rutina diaria. El autor, en cambio, tiene que anularse a sí mismo para poseer al otro - la novela es siempre, incluso la autobiográfica, la historia del otro ${ }^{16}$-; encierra su persona fuera de la maleta para contar el mundo aparte contenido en ella. En la frase inicial del Quijote tenemos un residuo de la operación de exclusión de la persona del escritor; en el «no quiero» de "En un lugar de la Mancha de cuyo nombre no quiero acordarme» nos es dado escuchar, a parte de los ecos romanceriles, la voluntad de extromisión de los afectos, las molestias de la cotidianidad, en la labor del autor.

El autor también se ha de recoger, como hacen sus personajes nómadas con la maleta, para su personal trayecto discursivo. Ese recogimiento necesario para la escritura es el que pudiera estar simbolizado en la maleta de la venta, en la de Cardenio y en otras. Los párrafos que siguen pretenden explorar esta hipótesis de interpretación.

SEGUNDA PARTE DE LA ARENGA. OTROS BULTOS DE MENOR IMPORTANCIA

Empezaré la segunda parte de mi arenga, excluyendo de mi depósito de equipajes los bultos de menor «momento y considera-

15 EDWARD W. SAID, Beginnings. Intention and Method. New York, Basic Books, 1975 , pp. 84 y ss.

${ }_{16}$ Cfr. Michail BACHTIN, L'autore e l'eroe. Teoria letteraria e scienze umane. Torino, Einaudi, 1988 [Estetika slovesnogo tvorcestva, Moskva, 1979], pp. 168-173. 
ción». La maleta resulta un contenedor especializado en el transporte de la literatura, con alguna que otra concesión a las camisas limpias. Cuando se trata del condumio, el recipiente de viaje suelen ser las alforjas, casi siempre asociadas al sintagma "bien proveídas», al que en una ocasión se añade un expresivo «de cosas tocantes a la bucólica» [II,7,630], en clara alusión a la cavidad oral a la que van destinadas las «cosas». El dinero o las joyas se transportan en la faltriquera o la ventrera:

Acudieron los bandoleros a espulgar al rucio, y a no dejarle ninguna cosa de cuantas en las alforjas y la maleta traía; y avínole bien a Sancho que en una ventrera que tenía ceñida venían los escudos del duque y los que habían sacado de su tierra [II,60,1119].

Si los objetos de valor van acompañados de ropa se les reserva la almohada (más propiamente, la funda de ella que se usaba como valija improvisada), o cuando menos eso es lo que hace Dorotea:

Luego, al momento, encerré en una almohada de lienzo un vestido de mujer, y algunas joyas y dineros, por lo que podía suceder. Y en el silencio de aquella noche, sin dar cuenta a mi traidora doncella, salí de mi casa, acompañada de mi criado y de muchas imaginaciones, y me puse en camino de la ciudad a pie [I,28,309].

Nos lo confirma, más adelante, incurriendo en contradicción — dicho sea de paso-, el narrador:

Sacó luego Dorotea de su almohada una saya entera de cierta telilla rica y una mantellina de otra vistosa tela verde, y de una cajita un collar y otras joyas, con que en un instante se adornó de manera que una rica y gran señora parecía. Todo aquello, y más, dijo que había sacado de su casa para lo que se ofreciese, y que hasta entonces no se le había ofrecido ocasión de habello menester. [I,29,316]

En su momento, Dorotea, y bien lo sabría ella, no dijo que en su almohada hubieran hallado espacio prendas de «rica y gran señora». A no tener yo otros temas en que ocuparme, dedicárame a escudriñar las entretelas de esta almohada y este descuido tan sabroso, que tal vez me llevara a probar que la trama caballeresca de Micomicona fue un añadido de última hora que Cervantes hizo para integrar la historia de Cardenio y Dorotea en la de don Quijote. Pero, como ya lo dejé apuntado en otro lugar ${ }^{17}$, no quiero divertirme del camino principal, y vuelvo a mi consigna de maletas, pa-

17 El Quijote en ciernes. Los descuidos de Cervantes y las fases de elaboración textual. Alessandria, Dell'Orso, 1990. 
sando previamente por el Parnaso. En cuyo Viaje menciona Cervantes explícitamente su maleta:

\section{La maleta del Viaje del Parnaso}

Pero, para la carga de un poeta, siempre ligera, cualquier bestia puede llevarla, pues carece de maleta $^{18}$.

Probablemente aún resuenen en los oídos de los oidores los ecos de la celebración noventayochista, a los que me remito para subrayar el parentesco con el «ligero de equipaje» de Antonio Machado. Como vemos, ya para Cervantes la maleta vacía era metonimia del poeta sin medios, pero también, me parece a mí, metáfora de la escritura, que ha de despojarse de las "golosinas de propiedad» del mundo ${ }^{19}$ para poder entrar en la dinámica de la aumentación. Y luego, ante Mercurio, Cervantes se diría que confirma esta interpretación, amén de aludir a su escasez de medios real:

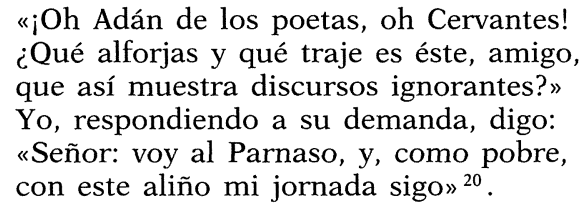

La imagen de la maleta en el Viaje de Parnaso ayuda a sostener la interpretación que doy a las del Quijote, o sea, que son la metáfora de la escritura. Si confrontamos la historia de El curioso impertinente con las otras historias interpoladas en el Quijote de 1605, todos relatos orales, nos damos cuenta de que una serie de implicaciones de tipo estructural la diferencian de las otras. Las demás interpolaciones tienen un emisor que coincide con el autor ficticio: en el momento en que las enuncia las produce; la performance se confunde con el texto. El curioso impertinente, en cambio, tiene un emisor que no es el autor, es solamente un lector más; el relato se convierte en la narración del escrito, pura palabra referida, sin acción, sin más referente que el papel que lo contiene. Es producto de la voz y no de los actos, del decir y no del hacer. Los textos de

18 El viaje del Parnaso, vv. 70-73, en Obras completas, ed. de Ángel VALbuena Prat. Madrid, Aguilar, $1967^{15}$, pp. 65-108, [p. 68].

19 Cfr. San JuAn de la CruZ, Epistolario, en Obras de San Juan de la Cruz. Madrid, Apostolado de la Prensa, 1954, p. 874.

20 El viaje del Parnaso, vv. 203-207, cit., p. 68. 
la maleta de la venta serían iterables en el mundo posible del Quijote; la lectura de El curioso impertinente se podría repetir ad libitum, porque en cuanto texto escrito nació en ausencia del destinatario y presuponiendo la futura ausencia del autor ${ }^{21}$; el destinatario puede variar cuantas veces se quiera; el autor no debe certificar el texto con su presencia. Los demás relatos interpolados existen para que haya una interacción entre el emisor, que coincide con el protagonista-autor, y el destinatario, de la que resulta la solución del caso narrado: Cardenio y Dorotea resuelven sus dramas gracias a la pariticipación del auditorio; el cautivo encuentra a su familia merced a la intermediación del cura, que ha escuchado su historia; Claudia Jerónima encuentra a su padre Ricote y rescata a su novio del cautiverio argelino, por la intervención de los que han escuchado su historia, etc. Los relatos interpolados de índole oral prevén la enunciación única; la posible segunda enunciación ya incluiría el final que la primera no tenía y una visión de conjunto que haría cambiar la impregnación ética del relato, contenida, por ejemplo, en las consideraciones vertidas por los personajes acerca de los demás, en las apreciaciones sobre la dimensión moral del caso por parte del narrador, etc., que son los indicadores textuales que conducen a la intervención de los que escuchan. El contenido ético del relato oral funciona como un arma de seducción sobre los oidores; los juicios del narrador-protagonista se traducen en acciones del destinatario oidor; sus palabras se convierten en hechos ajenos; el simulacro de significado transcendente que alberga el relato oral deviene colaboración fáctica del auditorio. Los textos escritos se extrovierten en el juicio del destinatario, mientras que los orales encuentran su valoración ética en la participación emotiva del auditorio.

\section{LA ESCRITURA DEL ORDEN}

El curioso impertinente, en cuanto texto escrito que asume la ausencia del autor como uno de sus componentes estructurales, que rompe el vínculo entre la persona del emisor y el texto, para quedar reducido al puro control de la aumentación de la palabra en su discurso, necesita el juicio conclusivo del cura para rellenarse del sentido transcendente que la escritura le niega:

- Bien - dijo el cura - me parece esta novela, pero no me puedo persuadir que esto sea verdad; y si es fingido, fingió mal el autor, porque no

\footnotetext{
21 DERRIDA, op. cit., pp. 404-5.
} 
se puede imaginar que haya marido tan necio que quiera hacer tan costosa experiencia como Anselmo. Si este caso se pusiera entre un galán y una dama, pudiérase llevar, pero entre marido y mujer, algo tiene del imposible; y, en lo que toca al modo de contarle, no me descontenta. $[\mathrm{I}, 35,400]$

El cura dice que ese caso es imposible entre cristianos, que pertenece a un mundo posible, en una palabra, que ese signo no posee un referente externo. Un modo de decir que se trata de un texto escrito. Todos los escritos carecen potencialmente de referente; que lo tengan o no es accesorio; lo fundamental es que se generan en la distancia del objeto evocado. En realidad, el cura no da un juicio ético o estético, como parece pretender, sino que está reflexionando sobre las condiciones de existencia de la escritura. Pero Pérez está diciendo que, al no poder existir el caso, los presentes no pueden intervenir en él, ni tampoco extraer un precepto moral. Es decir, está enunciando un principio rector de toda escritura, que, por hallar fundamento en una doble ausencia (la del autor y la del objeto designado), no puede ser depositaria de más significado transcendente que el que el lector le quiera atribuir con la lectura.

La cerrazón de la escritura, su inclusión en un espacio cerrado, como el que delimita la enunciación, hecho de exclusiones de otros temas, de otras pulsiones, en una palabra, de la vida, es lo que le consiente llevar a cabo el proyecto textual, que implica una constricción de la realidad en el interior de un orden discursivo y un canon de representación. Eso es lo que simboliza la maleta, haciéndolo concreto y material. En los tres casos analizados - la maleta de Cardenio, la de la venta, los cartapacios que contienen la historia de don Quijote-, el recipiente de los textos subraya la cualidad espacial que los extrapola de los demás elementos de la cadena contextual ${ }^{22}$ y los transporta en el interior de otro texto.

Los relatos de la historia del cautivo y el de Dorotea y Fernando no pueden ser extrapolados de su contexto. Nadie se los llevará a su casa, como hace el cura con el manuscrito de Rinconete $y$ Cortadillo, un objeto que puede ser evaluado estéticamente e incluso crematísticamente, al igual que el manuscrito de Cide Hamete, otro texto conservado en un contenedor:

Compré al muchacho todos los papeles y cartapacios por medio real; que, si él tuviera discreción y supiera lo que yo los deseaba, bien se pudiera prometer y llevar más de seis reales de la compra $[I, 9,101]$.

22 DERRIDA, op. cit., pp. 406-7. 
A ese coste hay que añadirle el de la traducción:

\footnotetext{
Apartéme luego con el morisco por el claustro de la iglesia mayor, y roguéle me volviese aquellos cartapacios, todos los que trataban de don Quijote, en lengua castellana, sin quitarles ni añadirles nada, ofreciéndole la paga que él quisiese. Contentóse con dos arrobas de pasas y dos fanegas de trigo, y prometió de traducirlos bien y fielmente y con mucha brevedad [Ibidem].
}

Aunque, en fin de cuentas, todo el Quijote es un texto regalado, entregado al lector por el autor en el prólogo:

Sólo quisiera dártela [la historia] monda y desnuda, sin el ornato de prólogo, ni de la inumerabilidad y catálogo de los acostumbrados sonetos [I, prólogo, 12. Énfasis mío.]

El manuscrito original se halla protegido en varios cartapacios, objeto escritural por excelencia, cerrado en sí mismo, completo y transportable, como una maleta. También en este caso el manuscrito podría tener otras lecturas posibles y no sólo la del morisco traductor; en efecto, el segundo autor le enmienda la plana de vez en cuando, o bien completa sus informaciones con otras fuentes documentales; eso sin llegar a suponer que el sabio Alisolán de Avellaneda leyera la versión de Cide Hamete. Es, por tanto, iterable en la medida en que también él separa al emisor de su receptor.

La capacidad de la escritura de extrapolarse del contexto de emisión y de recepción le confiere el poder de análisis de la realidad del que surge el orden del discurso. En otras palabras, la distancia del mundo, requerida por el proyecto mismo del decir, posibilita la elaboración de un discurso ordenado sobre el mundo, que lo transciende y lo consigna al universo de los significados del autor como un objeto semiótico más. Los tres manuscritos aparecen en contextos espaciales donde reina el caos: los cartapacios arábigos en el Alcaná de Toledo, caja de resonancia de tres diferentes culturas, en que todo se vende y todo se compra; la valija de Cardenio en Sierra Morena, espacio anímico y salvaje por excelencia; la maleta de Cervantes en la venta de las mil pendencias y robos, lugar de encuentros para viandantes al margen y en el respeto de la ley, unidos por el mayor acatamiento de la ley personal que la estatal. Hay un ejemplo que no es de maletas, sino de catafalcos, que puede ayudarnos a comprender mejor la relación entre la escritura y su contexto espacial. En el entierro de Grisóstomo, entre dos altas peñas, a la luz incierta del alba, Vivaldo da lectura a la Canción desesperada, uno de los poemas contenidos en las andas del muerto, en «algunos libros y muchos papeles abiertos y cerrados» 
$[I, 13,133]$. El lugar es el ónfalos del amor de Grisóstomo: allí habló a Marcela por primera vez, allí le declaró su amor, allí fue desdeñado, allí murió y allí quiere ser enterrado. En el ónfalos se anulan el tiempo y el espacio: pasado, presente y futuro del autor se condensan en los escritos, en aquel lugar desordenado que contiene las andas que contienen los papeles que contienen la intimidad de su autor; los del cortejo, a su vez, se hallan como suspendidos en la verticalidad del espacio, pues van bajando "por la quiebra que dos altas montañas hacían» [I,13,133]. En un espacio acotado, sin ley, salvaje, la escritura pone orden en el caos; en su crisol se acendran los significados del tiempo y el espacio; con su luz ilumina la vida de los personajes.

\section{PETICIÓN DE PENA Y AVISO FINAL}

En conclusión de mi arenga, señorías, confirmo los cargos contra el acusado, a saber: propagador anacrónico de una idea de la literatura exclusivamente moderna, autor consciente de su función y su responsabilidad, peligroso revolucionario de los modos de decir, y difusor del vicio de la lectura compulsiva. Por todo ello merecería que los contenidos de sus maletas fueran «condenados a galeras por todos los días de su vida», al parecer inmortal. Pero no siendo yo quién para solicitar semejante pena, me limito a advertir a sus señorías que, si no quieren caer víctimas de un vicio irreparable, se abstengan de leer los papeles de las maletas abandonadas en estas ventas de la Mancha que nos albergan.

José MANUEl MARTín MoRÁN Universidad del Piamonte Oriental 